\title{
PERSEPSI MASYARAKAT TERHADAP AGRIBISNIS SAYURAN METODE HIDROPONIK STARTERKIT WICK DI KOTA KENDARI
}

\section{PERCEPTION OF SOCIETY IN THE HIDROPONIK STARTERKIT WICK PROGRAM IN WAWOWANGGU VILLAGE, CITY OF KENDARI}

\author{
Asriani $^{1 *}$, Wa Embe ${ }^{1}$, Fitria Napu ${ }^{1}$, Dhian Herdhiansyah ${ }^{2}$ \\ ${ }^{1}$ Fakultas Pertanian, Universitas Muhammadiyah Kendari \\ Jl. KH. Ahmad Dahlan No. 10 Kendari \\ ${ }^{2}$ Fakultas Pertanian, Universitas Halu Oleo Kendari \\ Jl. H.E.A.Mokodompit Kampus Baru Anduonohu Kendari \\ *Email: asriani_umk@yahoo.co.id
}

(Diterima 21-08-2019; Disetujui 29-10-2019)

\begin{abstract}
ABSTRAK
Konsumsi sayur di kalangan masyarakat terus mengalami peningkatan seiring dengan peningkatan jumlah penduduk. Hidroponik merupakan inovasi di bidang pertanian yang dikembangkan untuk meningkatkan produksi tanaman sayur dalam rangka mendukung ketahanan pangan nasional. Penelitian ini bertujuan untuk mengetahui persepsi masyarakat pada metode Hidroponik Starterkit Wick tanaman sayuran. Lokasi penelitian dilakukan di Kelurahan Wawowanggu Kota Kendari. Pengambilan sampel dilakukan dengan teknik purposive sampling. Metode yang digunakan dalam penelitian adalah metode analisis deskriptif kualitatif dengan Skala Likert yang digunakan untuk mengukur sikap, pendapat dan persepsi masyarakat terhadap metode Hidroponik Starterkit Wick tanaman sayuran. Berdasarkan hasil penelitian diperoleh persepsi masyarakat terhadap program Hidroponik Starterkit Wick tanaman sayuran berdasarkan faktor-faktor yakni pemanfaatan lahan sempit, kualitas baik, bebas dari hama dan penyakit, praktis, banyak nutrisi, pertumbuhan tanaman yang cepat, cocok untuk daerah perkotaan dan sebagai agrowisata. Secara umum dan keseluruhan persepsi masyarakat terhadap metode hidroponik system starterkit wick berada pada nilai rata rata 3,58 dengan kategori tinggi.
\end{abstract}

Kata kunci: Persepsi, konsumen, hidroponik, starterkit wick

\begin{abstract}
Consumption of vegetables in the community continues to increase along with the increase in population. Hydroponics is an innovation in agriculture developed to increase vegetable production in the context of supporting national food security. This study aims to determine public perception on the Starterkit Wick Hydroponic method of vegetable plants. The location of the study was conducted in Wawowanggu District, Kendari City. Sampling was done by purposive sampling technique. The method used in this research is a qualitative descriptive analysis method with a Likert Scale used to measure attitudes, opinions and people's perceptions of the Hydroponic Wick Starterkit method of vegetable plants. Based on the research results obtained by community perceptions of the Starterkit Wick Hydroponics vegetable plants based on factors such as narrow land use, good quality, free of pests and diseases, practical, many nutrients, rapid plant growth, suitable for urban areas and as agro-tourism. In general and overall public perceptions of the hydroponic method for starterkit wick systems are at an average value of 3.58 with high categories.
\end{abstract}

Keywords: Perception, consumers, hydroponics, starterkit wick 


\section{PENDAHULUAN}

Hidroponik merupakan budidaya menanam dengan memanfaatkan media air tanpa menggunakan tanah dengan menekankan pada pemenuhan kebutuhan nutrisi bagi tanaman. Hidroponik merupakan metode bercocok tanam yang biasanya digunakan untuk menanam sayuran sebagai upaya untuk memenuhi sumber vitamin dan mineral masyarakat sekaligus dapat memanfaatkan pekarangan yang sempit. Adapun tanaman yang sering ditanam dengan menggunakan sistem hidroponik adalah tanaman sayuran berupa sawi, bayam, selada dan kangkung.

Adapun tujuan dari kegiatan ini adalah untuk memperkenalkan metode budidaya hidroponik kepada masyarakat kelurahan Wowawanggu tentang cara budidaya hidroponik dengan menggunakan metode Wick secara sederhana. Dalam kegiatan ini target yang ingin dicapai adalah terbentuknya kelompok masyarakat yang mampu menerapkan sistem penanaman sayuran secara hidroponik. Kegiatan ini dilakukan melalui sosialisasi dan pengenalan program serta penyampaian materi, melaksanakan aplikasi di lapangan dari hasil sosialisasi dan pengenalan, monitoring pelaksanaan program, evaluasi.

Ketersediaan lahan untuk pertanian saat ini semakin sempit, khususnya di daerah perkotaan.selain karena masalah di atas, masih banyak terjadi konversi lahan pertanian menjadi perumahan dan industry di daerah yang potensial. Meningkatnya pencemaran lingkungan oleh pestisida hasil pertanian dan limbah rumah tangga juga menjadi penyebab lingkungan di daerah perkotaan saat ini menjadi bertambah buruk. Masalah tersebut ditambah dengan belum optimalnya metode pertanian tradisional dalam memanfaatkan matahari sementara kebutuhan akan sayur-sayuran organik di masyarakat semakin meningkat.

Kelurahan Wowawanggu merupakan salah satu wilayah di Kota kendari yang berada di Kecamatan Kadia. Daerah tersebut padat penduduk perumahan, namun banyak terdapat lahan kosong yang tidak dimanfaatkan dengan baik, sehingga menjadi peluang dalam pengembangan pemanfaatan sayur dengan metode hidroponik.

Hidroponik adalah lahan budidaya pertanian tanpa menggunakan media tanah, sehingga hidroponik merupakan aktivitas pertanian yang dijalankan dengan menggunakan air sebagai 
medium untuk menggantikan tanah. Sehingga sistem bercocok tanam secara hidroponik dapat memanfaatkan lahan yang sempit.

Dengan semakin terbatasnya lahan untuk perumahan, maka makin sempit pula luas pekarangan yang dimiliki setiap rumah terutama di daerah perkotaan. Makin menyusutnya lahan terbuka menyebabkan masyarakat urban makin sulit untuk memelihara tanaman dan membuat taman. Terlebih lagi di daerah perkotaan sulit untuk mendapatkan tanah yang subur untuk media pertanaman, budidaya secara hidroponik merupakan suatu alternatif yang dapat diterapkan.

Informasi tentang perkembangan sistem hidroponik di Indonesia masih sangat minim, hal ini disebabkan oleh kurangnya penyuluhan tentang kelebihan sistem hidroponik pada lahan sempit. Hidroponik membutuhkan produk yang mutakhir, investasi yang tinggi serta keahlian yang khusus. Faktor tersebut yang menghambat peluang pertanian secara hidroponik (Roidah, 2014).

Hidroponik sebagai salah satu bentuk budidaya tanaman di daerah perkotaan, antara lain bertujuan agar usaha penyediaan tanaman sayur-sayuran dan buah-buahan untuk memenuhi gizi keluarga di perkotaan dapat terpenuhi dan juga akan menekan biaya untuk membelinya. Hidropnik diharapkan dapat meningkatkan pendapatan dan efisiensi dalam penggunaan lahan serta dapat menambah keserasian dan kenyamanan atau meningkatkan kualitas lingkungan kota.

Hidroponik merupakan salah satu cara bercocok tanam yang memanfaatkan air sebagai media nutrisi yang akan langsung diserap oleh tanaman sebagai penunjang tumbuh tanaman. Hidroponik Bisa dilakukan di lahan terbatas perkotaan. Nurtrisi pada hidroponik diperoleh dengan mencampurkan formula cair A dan B, biasa disebut dengan pupuk AB Mix (Rakhman dkk, 2015).

Sistem hidroponik wick atau sumbu merupakan suatu sistem pengairan dengan menggunakan prinsip kapilaritas. Sistem sumbu dalam teknik hidroponik dikenal sebagai sistem pasif karena tidak ada bagian yang bergerak, kecuali air yang mengalir melalui saluran kapiler dari sumbu yang digunakan. Teknik ini merupakan teknik yang mudah diterapkan dan tidak membutuhkan biaya yang banyak dalam pengadaan alatnya (Yuliantika, dan Kusuma, 2017). 


\section{METODE PENELITIAN}

Penelitian dilakukan di Kelurahan Wawowanggu Kota Kendari. Pemilihan lokasi dilakukan secara sengaja (purposive) (Singarimbun dan Effendi, 1995) dengan pertimbangan bahwa Kelurahan Wowawanggu telah mulai melakukan pengembangan tanaman hidroponik dan merupakan peserta pelatihan metode Hidroponik Starterkit Wick tanaman sayuran. Pengambilan sampel dalam penelitian ini adalah metode teknik purposive sampling yaitu masyarakat dari peserta pelatihan yang berjumlah 20 orang.

Jenis data yang digunakan dalam penelitian ini yaitu data primer dan sekunder. Data primer diperoleh melalui wawancara langsung menggunakan kuesioner, sedangkan data sekunder diperoleh instansi terkait literature yang berhubungan dengan penelitian. Metode yang digunakan dalam penelitian ini adalah metode analisis deskriptif (Nazir, 2014). Analisis deskriptif kuantitatif digunakan untuk mengetahui persepsi masyarakat program pelatihan metode Hidroponik Starterkit Wick tanaman sayuran.

\section{Objek dan Tempat Penelitian}

Adapun objek penelitian mengenai persepsi masyarakat terhadap metode Hidroponik Starterkit Wick adalah masyarakat yang sedang melakukan pelatihan tentang hidroponik, adapun tempat penelitian adalah Kelurahan Wowawanggu dengan pertimbangan daerah tersebut sedang mengembangkan hirdoponik tanaman sayuran.

Dalam penelitian ini yang digunakan adalah Skala Likert. Skala Likert digunakan untuk mengukur sikap, pendapat dan persepsi seseorang atau sekelompok masyarakat tentang fenomena sosial. Dalam Penelitian phenomena sosial ini telah ditetapkan secara spesifik oleh peneliti, yang selanjutnya disebut sebagai variabel penelitian (Sugiyono, 2011).

\section{Persepsi Masyarakat Hidroponik} Starterkit Wick

Berdasarkan hasil pengamatan persepsi terhadap masyarakat Wawowanggu terhadap program metode Hidroponik Starterkit Wick tanaman sayuran merupakan proses pemahaman makna dari dalam memberikan nilai atas suatu informasi terhadap peristiwa dalam obyek yang terdiri dari beberapa indikator penilai objek yang diamati. 
Persepsi masyarakat terhadap metode Hidroponik Starterkit Wick diukur dengan pertanyaan-pertanyaan yang terdiri atas 8 tema yang termasuk dalam faktor internal dan faktor ekternal sebagaimana terlihat pada Tabel 1 .

Tabel 1. Faktor Internal dan Eksternal Persepsi Masyarakat Terhadap Metode Hidroponik Starterkit Wick

\begin{tabular}{lll}
\hline & Indikator & \\
\hline Faktor Internal & Pemanfaatan Lahan & \\
& Kualitas Baik & \\
& Bebas Hama dan Penyakit \\
& Kemudahan dalam & \\
& Budidaya & \\
& Banyak Nutrisi & \\
& Pertumbuhan & Tanaman \\
& Cepat & \\
\hline Faktor Eksternal & Cocok Untuk Perkotaan \\
& Agrowisata \\
\hline
\end{tabular}

Hasil yang diperoleh dikelompokkan dalam 3 tingkatan skor dengan kriteria persepsi yakni tinggi, sedang dan rendah yang diperoleh melalui rumus interval sebagai berikut (Sugiyono, 2011):

$$
\mathbf{I}=\mathbf{R} / \mathbf{K}
$$

Keterangan: $\mathrm{I}=$ Interval Kelas

$$
\begin{aligned}
& \mathrm{R}=\text { Rentang } \\
& \mathrm{K}=\text { Banyaknya Kelas }
\end{aligned}
$$

Berdasarkan rumus diperoleh tingkatan skor persepsi :
a. Skor $1,00-2,00=\operatorname{Rendah}(\mathrm{R})$
b. Skor $2,01-3,00=$ Sedang $(\mathrm{S})$
c. Skor $3,01-4,00=$ Tinggi $(\mathrm{T})$

\section{Analisis Data}

Untuk mengetahui persepsi masyarakat terhadap metode Hidroponik Starterkit Wick di Kelurahan Wowawanggu dilakukan teknik analisis deskriptif dengan pengukuran Skala Likert dengan tabel data dan angka. Adapun jumlah pertanyaan untuk mengukur persepsi masyarakat kelurahan Wowawanggu yang terdiri atas 8 pertanyaan baik yang berasal dari faktor internal maupun dari faktor eksternal. Jumlah responden sebanyak 20 orang yang sedang mengikuti pelatihan hidroponik. Adapun jawaban dari pertanyaan terhadap responden kemudian dikategorikan sebagaimana terlihat pada Tabel 2.

\begin{tabular}{ccc} 
Tabel 2. & $\begin{array}{c}\text { Kategori dan } \\
\text { Masyarakat } \\
\text { Hidroponik Startekit Wick }\end{array}$ \\
\hline SS & Sangat Setuju & $\begin{array}{c}\text { Persepsi } \\
\text { Metode }\end{array}$ \\
ST & Setuju & 4 \\
RR & Ragu-ragu & 3 \\
TS & Tidak Setuju & 2 \\
STS & Sangat Tidak Setuju & 1 \\
\hline
\end{tabular}

\section{HASIL DAN PEMBAHASAN}

Persepsi petani terhadap Hidroponik metode Starterkit Wick di Kecamatan Wawowanggu

Secara umum persepsi masyarakat terhadap Hidroponik Startekit Wick di Kelurahan Wowawanggu sebesar 3,95 (skala Likert) berkategori tinggi. Hal 
tersebut terlihat dari penilaian pernyataan yang mayoritas responden memberikan jawaban tepat pada pertanyaan yang diajukan.

Tabel 3. Persepsi Masyarakat Terhadap Metode Hidroponik Startekit Wick

\begin{tabular}{lccccccc}
\hline Persepsi Terhadap Metode & SS & ST & RR & TS & STS & \multirow{2}{*}{ Persepsi } & \multirow{2}{*}{ Kategori } \\
Hidroponik Starterkit Wick & $\mathbf{5}$ & $\mathbf{4}$ & $\mathbf{3}$ & $\mathbf{2}$ & $\mathbf{1}$ & & \multirow{2}{*}{ Tinggi } \\
\hline Pemanfaatan Lahan Sempit & 4 & 10 & 2 & 2 & 2 & 3,60 & Tinggi \\
Kualitas Baik & 2 & 12 & 2 & 2 & 1 & 3,45 & Tinggi \\
Bebas Hama dan Penyakit & 5 & 9 & 3 & 1 & 2 & 3,70 & Tinggi \\
Kepraktisan & 7 & 7 & 4 & 1 & 1 & 3,95 & Sedang \\
Banyak Nutrisi & 2 & 4 & 4 & 5 & 5 & 2,60 & Tinggi \\
Pertumbuhan Tanaman Cepat & 3 & 9 & 5 & 2 & 1 & 3,75 & Tinggi \\
Cocok Untuk Perkotaan & 4 & 13 & 0 & 2 & 1 & 3,85 & Tinggi \\
Agrowisata & 6 & 10 & 0 & 2 & 2 & 3,80 & Tinggi \\
\hline Rata-rata & & & & & & $\mathbf{3 , 5 8}$ & \\
\hline
\end{tabular}

Berdasarkan hasil penelitian dapat dijelaskan bahwa konsumen memberikan penilaian paling tinggi terhadap metode Hidroponik Starterkit Wick untuk faktor internal, yakni: (1) pemanfaatan lahan sempit dengan nilai persepsi sebesar 3,60 dengan kategori tinggi, (2) kualitas baik nilai persepsi sebesar 3,45 dengan kategori tinggi, (3) bebas dari hama dan penyakit nilai persepsi sebesar 3,70 dengan kategori tinggi, (4) praktis dengan nilai persepsi sebesar 3,95 dengan kategori tinggi, (5) mengenai banyak nutrisi dengan nilai sebesar 2,60 kategori tinggi, (6) pertumbuhan tanaman yang cepat nilai persepsi sebesar 3,75 dengan kategori tinggi. Sementara itu pada faktor eksternal (7) cocok untuk daerah perkotaan dengan nilai 3,85 kategori tinggi, dan (8) agrowisata dengan nilai persepsi 3,80 kategori tinggi.

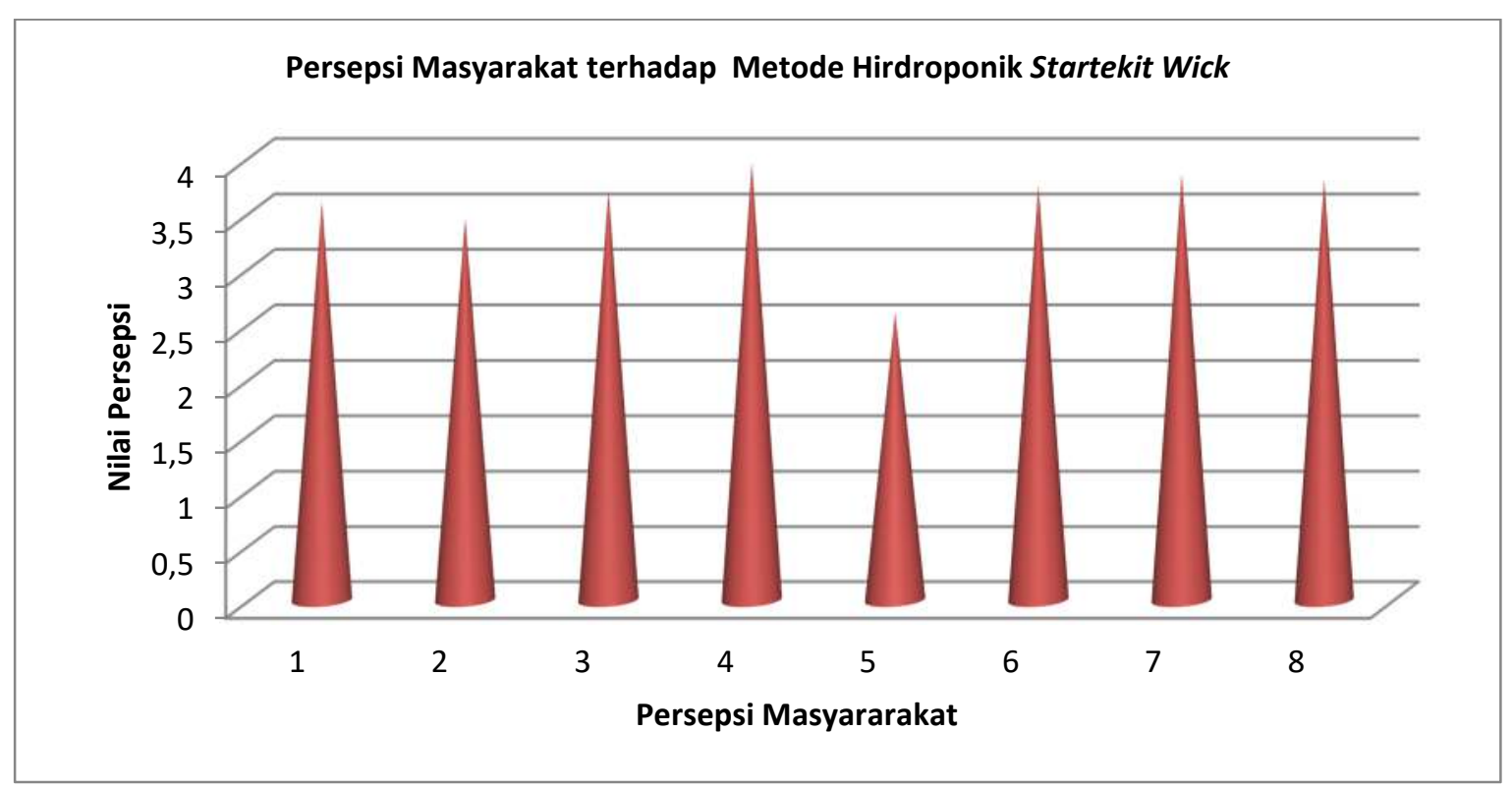

Gambar 1. Grafik Persepsi Masyarakat Terhadap Metode Hidroponik Starterkit Wick 
Sistem hidroponik wick atau sumbu merupakan suatu sistem pengairan dengan menggunakan prinsip kapilaritas. Sistem sumbu dalam teknik hidroponik dikenal sebagai sistem pasif karena tidak ada bagian yang bergerak, kecuali air

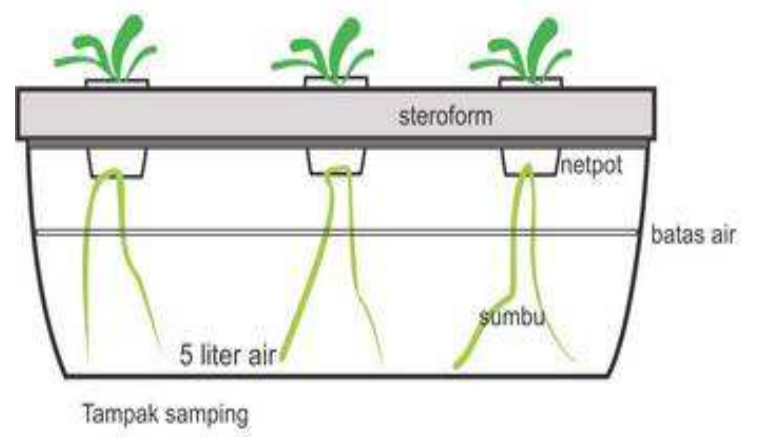

yang mengalir melalui saluran kapiler dari sumbu yang digunakan. Adapun hidroponik system Wick yang akan diterapkan sebagai solusi permasalahan mitra seperti Gambar 2.

Gambar 2. Metode Hodroponik Sistem Starterkit wick

\section{KESIMPULAN DAN SARAN}

\section{Kesimpulan}

Berdasarkan hasil kegiatan yang telah dilaksanakan, maka dapat diambil kesimpulan sebagai berikut: persepsi masayarakat terhadap pengembangan hidroponik metode starterkit wick tertinggi adalah persepsi tentang kepraktisan dengan nilai persepsi sebesar 3,95 yang termasuk kategori tinggi, sedangkan persepsi masayrakat terendah adalah mengenai banyaknaya nutrisi dengan nilai persepsi sebesar 2,60 kategori sedang. Secara umum persepsi masayarakat terhadap metode hidroponik

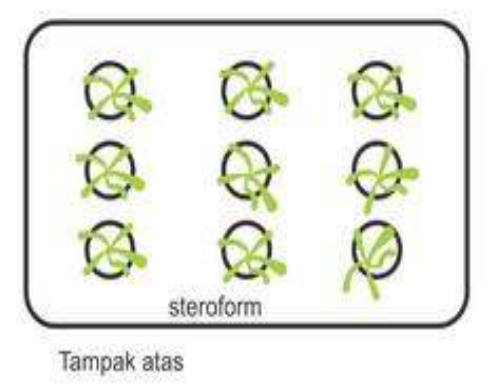

system starterkit wick berada pada nilai rata rata 3,58 dengan kategori tinggi.

\section{Saran}

Adapun saran dalam penelitian ini adalah metode hidroponik starterkit wick perlu dilakukan mengingat persepsi masayrakat terhadap metode tersbut sangat tinggi sehingga perlu untuk dikembangkan.

\section{DAFTAR PUSTAKA}

Nazir, M. 2014. Metode Penelitian. Bogor: Penerbit Ghalia Indonesia.

Rakhman, A., L. Budianto, R. Bustomi, dan K. Zen. 2015. Pertumbuhan Tanaman Sawi Menggunakan Sistem Hidroponik dan Akuaponik. 
Jurnal Teknik Pertanian Lampung, 4(4): 245-254.

Roidah,I . 2014. Pemanfaatan Lahan Dengan Menggunakan Sistem Hidroponik. Jurnal Universitas Tulungagung BONOROWO, 1(2): 43-49.

Singarimbun, M. dan Effendi, S. 1995. Metode Penelitian Survei. Jakarta: Pustaka LP3ES.
Sugiyono, 2011. Metode Penelitian Kuantitatif, Kualitatif, dan $R \& D$. Bandung: Alfabeta.

Yuliantika, I dan Kusuma, N. 2017. Efektivitas Media Tanam Dan Nutrisi Organik Dengan Sistem Hidroponik Wick Pada Tanaman Sawi Hijau. Prosiding Seminar Nasional SIMBIOSIS II, Universitas PGRI Madiun, 30 September 2017, pp. 228-238. 